\title{
México y el mexicano: Identidades colectivas de los orígenes
}

\author{
Juana Juárez Romero ${ }^{1}$ \\ Universidad Autónoma Metropolitana \\ juana@xanum.uam.mx
}

\begin{abstract}
Resumen
Presentamos algunos resultados de una investigación en la cual el objetivo era conocer: sí los orígenes asociados a México y al Mexicano eran los mismos. Suponíamos entonces la existencia de una cierta articulación entre estas dos ideas, sin embargo, reconocíamos la presencia de una contradicción constante entre la caracterización predominantemente positiva del país, y la caracterización tendencialmente negativa atribuida al Mexicano. En suma buscamos acercarnos al problema de las identidades del Mexicano a través de una aproximación diferente a las tendencias dominantes que nos proponen largas listas de inventarios en las cuales se documentan o se busca hacerlo, la manera de ser del Mexicano.
\end{abstract}

Así, recurrimos a la historia y a los mitos sobre el origen en busca de comprender: cómo se forjan estas creencias y qué forma tienen en la memoria colectiva. Presentamos aquí nuestros avances en el estudio, los cuales corresponden a las ideas y las opiniones de distintos grupos, en torno a los orígenes -historia y mitos- de México y del Mexicano.

Se presentan resultados de un cuestionario aplicado a 38 estudiantes de psicología social de la UAM-I, y a 38 trabajadores universitarios de la misma universidad. Se presentan también resultados de 18 entrevistas realizadas con obreros, comerciantes ambulantes y profesionistas de la delegación Iztapalapa. Los resultados nos permiten reconocer dos "perfiles" diferenciados en la organización de las respuestas asociadas a los orígenes de México y del Mexicano: Uno para caracterizar los orígenes de México y otro para caracterizar los orígenes del Mexicano. Igualmente nos permiten proponer la hipótesis sobre la existencia de representaciones colectivas en torno a cada uno de dichos orígenes. En suma nos permiten trazar nuevas preguntas y nuevas rutas en el estudio de un asunto siempre polémico, el de la identidad del mexicano.

Palabras clave: Orígenes, memoria e identidad colectiva

\section{Introducción}

El trabajo que presentamos a continuación parte de reconocer a los orígenes de una sociedad como punto esencial de definición de la identidad de los grupos, de "su carácter" y su destino colectivo. En

\footnotetext{
${ }^{1}$ Profesora-Investigadora de la Licenciatura en Psicología social, integrante del Area de Investigación en Psicología Política e Identidades, Depto. de Sociología. UAM-I. Estudiante de Doctorado en Psicología Social en la Universidad René Descartes, París V, Francia.
} 
efecto, a decir de Pablo Fernández (2002) "los grupos y sociedades establecidos asumen la existencia forzosa de un primer acontecimiento en donde se inicio tal grupo o sociedad. Ese es su origen, al cual retornan a cada tanto para de ahí sacar fuerzas y aliento y así poder proseguir. Toda vez que el acontecimiento representa el origen, constituye el significado más intenso de cualquier sociedad". Esto significa que el origen tiene a la vez un carácter simbólico y afectivo. Así, por su fuerza e intensidad el origen es más que una escena consignada en los libros, es más que un dato formando parte de la historia es parte de lo cotidiano, es símbolo que circula entre las cosas y las conversaciones, que a veces se asoma y otras asume una presencia discreta pero que no desaparece, que se transmite, se adapta y permanece.

En el caso de México, los orígenes, mejor aún los mitos del origen son parte de la historia oficial y de la historia en un sentido más amplio, y constituyen sin duda -a nivel simbólico- el punto de partida de la nación mexicana. Según E. Florescano (1996) tales mitos del origen de México han sido reproducidos para constituir una historia del pasado acorde con las condiciones socio-políticas del país.

En la medida en que la memoria colectiva es descrita por Halbwachs (1950) como "una reconstrucción del pasado que ajusta la imagen de viejos eventos a las creencias y necesidades espirituales del presente", los orígenes constituyen así un evento simbólico donde la memoria colectiva resulta un medio eficaz para comprender su fuerza y permanencia. Los orígenes modelan así las identidades colectivas de los grupos, y permanecen a través de dos lógicas cuya naturaleza es diferente: la de la memoria artificial, y aquella de la memora natural (Cisneros, 1990)². Así, estas dos formas de la memoria están determinadas no sólo por los contextos, las situaciones y el presente sino, y quizá de modo más importante, por la fuerza de los significados, de las lógicas propias depositadas en cada una de sus formas sea esta histórica o natural. Su permanencia a través, de diversas instituciones encargadas de garantizar su presencia, por un lado, y a través de practicas y saberes milenarios que posibilitan su transmisión, por el otro, hacen posible la convivencia de dos lógicas diferentes pero unidas en la tarea de brindar una identidad a los colectivos y a los grupos.

\section{Identidad nacional e idea de nación en México.}

Por otro lado, el reconocimiento, en el caso de México, de la existencia de una estrecha relación entre los orígenes y la nación mexicana nos hace evocar a Znanieckie (1944) según quien "Las fuerzas

2 Las memorias artificiales“... hay que considerar [en este caso] el arte clásico de la memoria, la técnica y los escenarios que involucran las nociones de sistema y teatro, que son fundamentos de la acción reconstructiva de los significados y símbolos sociales, la composición de imágenes, que por otra parte, se nutre de los pasados considerados históricos en una perspectiva temporal y es resultado de lógicas colectivas cuya permanencia configuran sus presentes como pensares históricos." Y las memorias naturales son descritas como: "...estas resultan de las exigencias inmediatas de los individuos; en tanto conjuntos abigarrados de múltiples elementos yuxtapuestos que permiten a las memorias conformar las rutas más estables del sentido común." (Cisneros, 1990: $116)$. 
psicológicas que forman lo que llamamos "nación" o "conciencia nacionales" son las ideas, creencias, emociones, impulsos e instintos ".

Más allá de las polémicas sobre la existencia de la nación y sus formas, la nación es un eje de sentido propio de las sociedades modernas que busca modelar las sociedades, orientar el cotidiano, determinar el destino colectivo de hombres y mujeres. Modo moderno de ordenar y clasificar el mundo, la idea de nación toma formas particulares dependiendo del contexto, de las situaciones y fuerzas diversas que gobiernan a la sociedad (Pérez-Agote, 1993). Adquiere también la forma de la cultura en la cual evoluciona, de modo que podemos observar diversas expresiones de un modelo que aspira a la homogeneidad, y que de todos maneras es funcional en la tarea de ordenar el mundo y sus relaciones (Hosbawn, 1992).

Nos proponemos entonces identificar las ideas, creencias, los símbolos que son asociados a los orígenes de la nación mexicana, las ideas o imágenes que dan un sentimiento de comunidad y de pertenencia según Anderson (1993), pero igualmente aquéllas asociadas al origen del mexicano. Suponemos que dichos objetos y/o símbolos de pertenencia se encuentran articulados a esos que son propios de la identidad nacional. Y es que aun cuando conocemos bien la dificultad de cernir un objeto como el de la identidad nacional, nos proponemos reconocerlo aquí desde su aspecto subjetivo, simbólico, desde ese espacio en donde el origen da sentido, por un lado a la idea de nación $y$, por otro lado, a la identidad nacional y/o ciudadana. La nación, es reconocida así como una entidad que constituye una fuente esencial de las identidades colectivas de nuestro tiempo. Así y más allá de la pertenencia inicial, de un individuo, a la familia, al ámbito del trabajo, al ámbito social y político, la nacionalidad constituye la entidad que engloba a todas las anteriores y dota a los individuos de una identidad particular, de modo que aun reconociendo las diferencias y la diversidad de los grupos en sociedad, dicha entidad tiende a crear una idea bajo la cual la homogeneidad es unidad, y en el caso que nos ocupa, encuentra una sola expresión: el ser mexicano. La nación, la idea de nación es en suma una categoría cuya función central es la organizar el mundo y sus relaciones

Así, la nación, la idea de nación, en tanto entidad ideológica y colectiva constituye un referente esencial en la organización del mundo y sus relaciones, y no puede ser concebida como una entidad distante o independiente de la identidad nacional.

Según Paéz et, al. (2000), la identidad nacional "son las memorias históricas compartidas, que corresponden a los mitos, a memorias de un pasado común, es decir que comparten una memoria colectiva de los orígenes". Y es esta manera de referir a la identidad nacional la que hemos elegido a fin de dar cuenta de los orígenes y los símbolos asociados a dicha identidad.

Dada su capacidad de organización y de integración la nación constituye un eje de sentido importante en la definición del pensamiento social de una sociedad, es por ello que proponemos estudiar los vínculos entre identidad nacional y la idea de nación en México desde una perspectiva que nos permita reconocer el vinculo entre el pensamiento social y la estructuración de una idea de nación.

\section{El pensamiento social: su organización}

Nuestro interés por la idea de nación y por el pensamiento social busca sentar así las bases a partir de las cuales nos sea posible indagar sobre la importancia de la historia en la definición y construcción de la identidad nacional en México. Suponemos así un vinculo entre la construcción del 
pensamiento social y la idea de nación, sin proponernos generalizar dicha asociación en el estudio de los problemas de la sociedad mexicana, nos parece que, en efecto, esta perspectiva nos permite contar con una imagen organizada de los distintos procesos y tiempos involucrados en un tema tan específico y a la vez tan amplio como es el de la construcción de las identidades en México.

Al referir al pensamiento social buscamos enfatizar a la realidad como producto de un proceso de construcción social, e insistir en su naturaleza simbólica y por ende, la de la sociedad. También es, para nosotros, una manera de enfatizar que, los distintos procesos que estudia nuestra disciplina como son las actitudes, las opiniones, las creencias, las representaciones sociales o la memoria forman parte de dicha entidad. Así que cuando estudiamos un proceso particular, damos cuenta en realidad de un elemento perteneciente a una entidad más compleja y más amplia que el proceso mismo que estudiamos, la del pensamiento social.

Donde el pensamiento social es, en consecuencia, producto de una cultura y un desarrollo social dado. $Y$ es que el pensamiento social no es producto de una elaboración espontánea, ni mera imagen o concepción del mundo y de la realidad, es sobre todo resultado de un momento dado, de las ideas, de las creencias que ordenan las relaciones entre los hombres en un grupo o sociedad. De modo que la lógica propia del pensamiento social tiene una razón de ser, tiene su fundamento en los hechos que dan sentido a los valores y aspiraciones de los hombres que conforman una sociedad. El trabajo de Bartlet (rééd.1995), sobre la memoria colectiva evidencia a la convencionalización como el instrumento y el proceso colectivo, a partir del cual se tejen las relaciones en el cotidiano, la continuidad de la identidad y la permanencia de los grupos. Es en ese espacio, mediante dicho proceso de convención que se definen las normas, los valores y las aspiraciones de un grupo. Es por ello que conviene contar con un marco en el cual sea posible comprender cómo los elementos que son nuestro objeto de reflexión y estudio se asocian, vinculan, pertenecen y se entretejen con corrientes de sentido que atraviesan a las sociedades.

La llustración 1, que presentamos busca ilustrar la manera en que concebimos se organiza el pensamiento social de cara a la idea de nación en México, como hemos insistido suponemos que tal

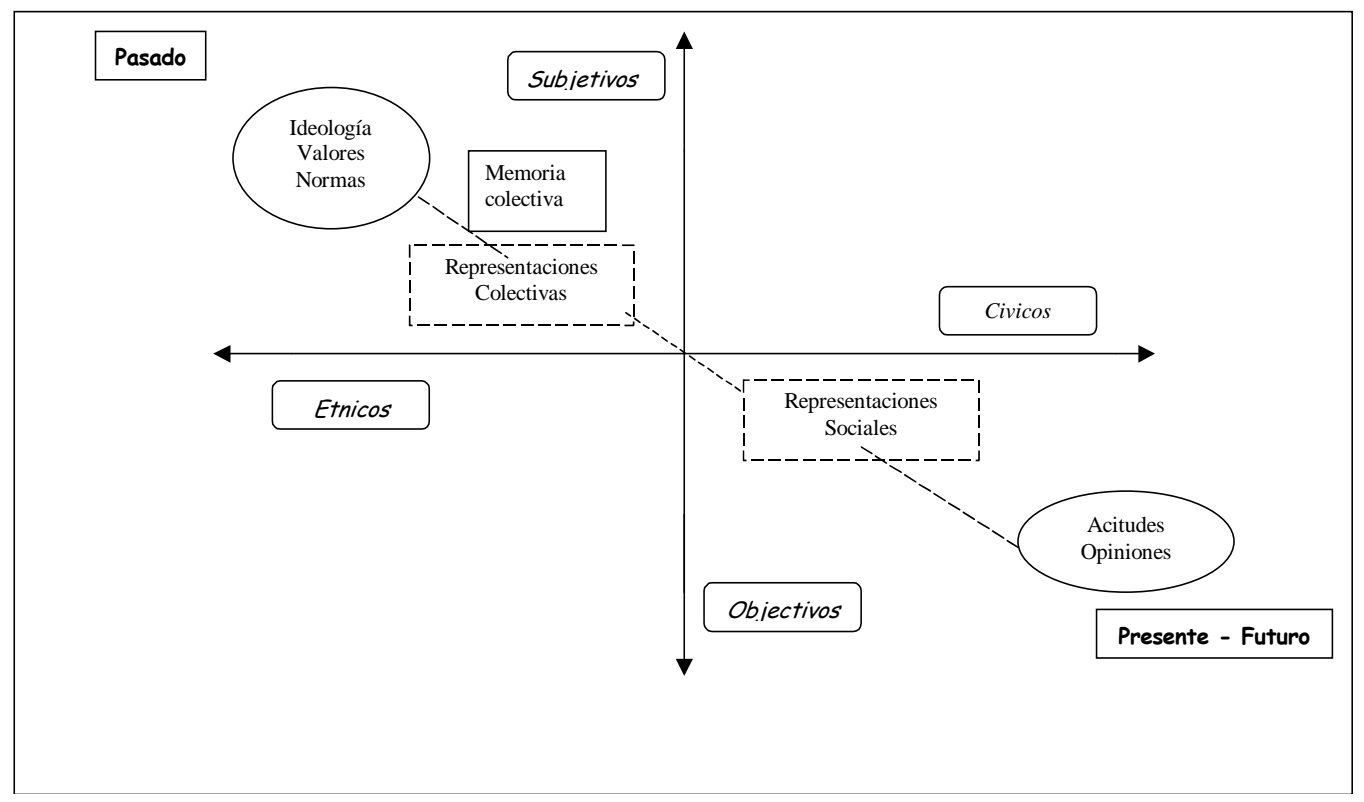

Ilustración 1. Organización del pensamiento social de los orígenes de la idea de nación. 
idea de nación juega un rol importante en la definición de la identidad no sólo del país sino también de sus ciudadanos.

Como puede observarse, en el extremo superior izquierdo se ubican tres elementos: en principio el tiempo pasado; el nivel genérico que deviene la esencia de los procesos más generales de la vida en sociedad, como son: la ideología y las creencias. Nos referimos aquí al apego de los grupos a una vida comunitaria donde lo colectivo adquiere forma a través de las costumbres y tradiciones de los grupos étnicos, practicas que son convertidas en valores y normas, las cuales inciden a su vez, en la definición de las relaciones entre los hombres y mujeres de un grupo social dado. Es desde aquí que se nutre el ciudadano pensador (Rouquette, 1988, 1994), ese que encuentra aquí informaciones y practicas, corrientes de sentido que vienen unas veces de los libros, otras de las montañas, de los saberes, practicas y tradiciones que se mantienen para nutrir el pensamiento colectivo.

La identidad es concebida aquí como saber compartido, así las tradiciones, las costumbres, las creencias se convierten en punto común de referencia, de identidad. La identidad y pertenencia a una categoría social es entonces y esencialmente concebida como producto del consenso (Baugnet, 1998), así lo colectivo es inspiración y definición de las identidades. Y claro es también el espacio donde encuentran, desde donde forjan las sociedades los recuerdos y los olvidos que explican y justifican el destino de sus pueblos.

Por otro lado, en el extremo inferior derecho, se ubican tres elementos: la línea del presente-futuro, el nivel especifico y los aspectos cívicos. Dichos elementos devienen el marco en el cual cobran forma las expresiones específicas del conocimiento de la realidad así como las relaciones entre los hombres y los grupos, es en este espacio donde la diferenciación se convierte en cualidad o característica resultado de la posición social que juega cada grupo frente a la dinámica social. Se forjan aquí las identidades grupales, aquí donde los roles establecidos desde el civismo establecen ya una clara línea entre, al menos, los gobernantes y los ciudadanos, los gobernados. Es desde aquí también que se difunde una concepción del ciudadano pensado, ese ciudadano concebido y promovido desde las instituciones del estado (Rouquette, 1988,1994)

Es también el cuadrante donde las practicas, las opiniones, las actitudes están asociadas a grupos o posiciones específicos dentro de la vida social cotidiana. Es en este espacio, donde se destacan los aspectos específicos y cívicos, y en donde la diferenciación, la heterogeneidad deviene regla esencial en lo cotidiano, por más que una tal diferenciación tenga como punto de definición lo colectivo, tal y como lo muestra Doise (1999), en su estudio sobre: el individualismo como representación colectiva. Así lo colectivo busca expresarse a través de la diferencia, la división social del trabajo, por ejemplo, se convierte en línea de diferenciación entre grupos al tiempo que forja en el interior de cada uno sentimientos de pertenencia, de unidad.

\section{Metodología}

Con la finalidad de indagar sobre el tipo de imágenes, así como para identificar los símbolos, los personajes y los eventos históricos que mejor caracterizan a México y al Mexicano. Y bajo el supuesto de que existe una articulación entre la idea de nación (de México) y del Mexicano realizamos 38 cuestionarios en estudiantes de psicología social, del último año de la carrera, de la 
UAM-I, en el D.F., y 38 en empleados de la misma universidad ${ }^{3}$. También realizamos una entrevista que buscaba profundizar en los resultados de nuestros cuestionarios, dicha entrevista se realizó con 6 obreros, 6 comerciantes ambulantes y 6 profesionistas de la delegación Iztapalapa en la ciudad de México.

Los cuestionarios. Se trata de un cuestionario que en la primera parte tiene una tarea de asociación, en un caso sobre México y en el otro, sobre el Mexicano. En la segunda parte se presentan listas de los símbolos, de personajes, y de hechos históricos recopilados previamente a través de entrevistas y cuestionarios abiertos, la tarea aquí es la de indicar cuál es para ellos el símbolo, personaje y evento histórico que mejor caracteriza a México, en un caso, al Mexicano en el otro. Los cuestionarios fueron aplicados cada uno a sujetos distintos.

La guía de entrevista, tiene como antecedente los resultados de los diversos cuestionarios y entrevistas previos sus objetos de indagación son dos: México y el Mexicano, símbolos, personajes, mitos, tradiciones y costumbres.

En el caso de los cuestionarios se realizó un análisis de contenido temático para clasificar la información, en las preguntas cerradas se obtuvieron frecuencias. En cuanto a las entrevistas, se utilizó el programa Atlas-Ti. Atlas-Ti, es un programa que constituye una herramienta para la realización del análisis de la información escrita y visual, dicho programa posibilita identificar los elementos que son propios para describir a un objeto así como las relaciones que son propias de dichos elementos. Se trata de construir familias de sentido a partir de las afirmaciones que nos proporcionan nuestros entrevistados para reconocerlas y nombrarlas.

\section{Resultados}

Presentamos enseguida, primero el tipo de referencias que se hacen de México y del Mexicano. Enseguida, se presentan los datos que dan cuenta de los símbolos que caracterizan dichos objetos, presentamos después, los datos que dan cuenta del evento histórico que sirve para explicar el origen de México y del Mexicano, los resultados se presentan a nivel de porcentajes. En este análisis de los datos el objetivo era únicamente el identificar el tipo elementos (cívicos, étnicos, religiosos) o bien su naturaleza (descriptiva o evaluativa), suponíamos que los componentes estarían los mimos y tendrían la misma naturaleza. Finalmente, se da cuenta de dos cuadros generados a través de Atlas-Ti que permiten organizar la información que sobre los orígenes de México y del Mexicano nos brindan nuestros entrevistados

\section{1 Imágenes de México y el Mexicano.}

En cuanto a las imágenes que de México se obtuvieron, se identificaron dos ejes que nos permitieron organizar la información obtenida. Por un lado, los aspectos cívicos (bandera, constitución, leyes, escudo) y étnicos (pirámides, indígenas, artesanías, el águila devorando una serpiente) de la nación,

${ }^{3}$ Con los resultados obtenidos mejoramos el instrumento y se aplico a 200 personas (100 estudiantes de psicología social y 100 empleados de la misma universidad). Los resultados son semejantes y no damos cuenta de ellos en esta comunicación. 
y por otro lado, evaluaciones (belleza, gran país, libertad, corrupción, contaminación) y descripciones (riquezas naturales, gente, diversidad, colores) en torno al país (grafica 1). Cabe destacar que aun cuando encontramos evaluaciones negativas del país, la tendencia de las evaluaciones, descripciones del país tiene una tendencia positiva.

En primer lugar se observa que son los aspectos cívicos (31.2\%) y de evaluación (35.5\%) los referentes más comunes para describir a la nación en los empleados, mientras que los aspectos cívicos(38.4\%) y los descriptivos (30.2\%) constituyen los referentes más comunes para describir a la nación en estudiantes. Finalmente, los aspectos étnicos constituyen el referente más frágil en las imágenes asociadas al país para las dos poblaciones (empleados 9.7\%, estudiantes 11.6\%). Si bien se detectan algunas diferencias sobre todo de cara al carácter descriptivo o evaluativo de las imágenes sobre México, dichas diferencias no parecen importantes.

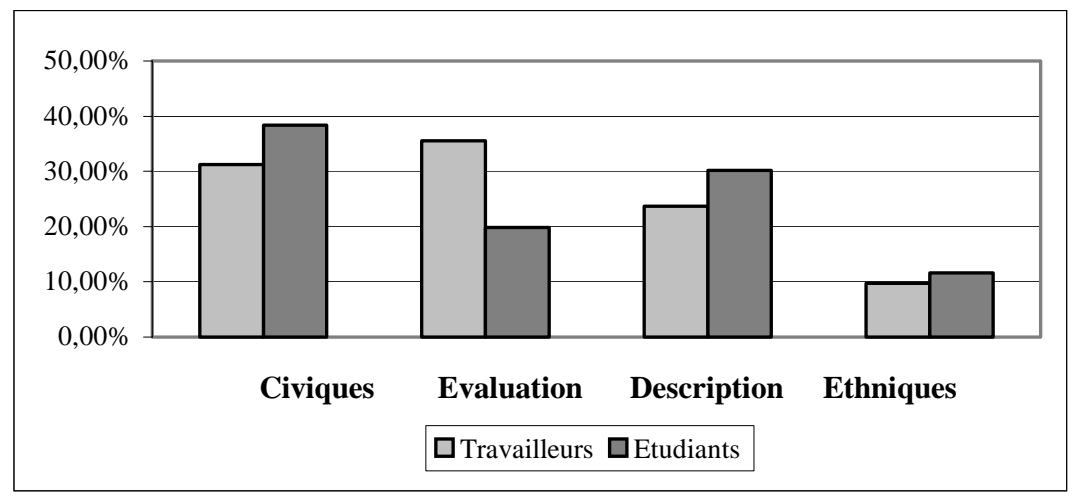

Gráfica 1. Las Imágenes de México según tipo de descripción. Porcentajes

Se presenta ahora una gráfica que resume el tipo de referentes que fueron asociados al Mexicano, donde dada la dificultad de clasificar las cualidades o características que sirven para describir al Mexicano, por ejemplo frente al termino conformista, que puede ser considerado como una descripción pero también como una evaluación. Decidimos identificar únicamente el carácter positivo o negativo de las palabras asociadas al Mexicano, y así obtuvimos la grafica 2.

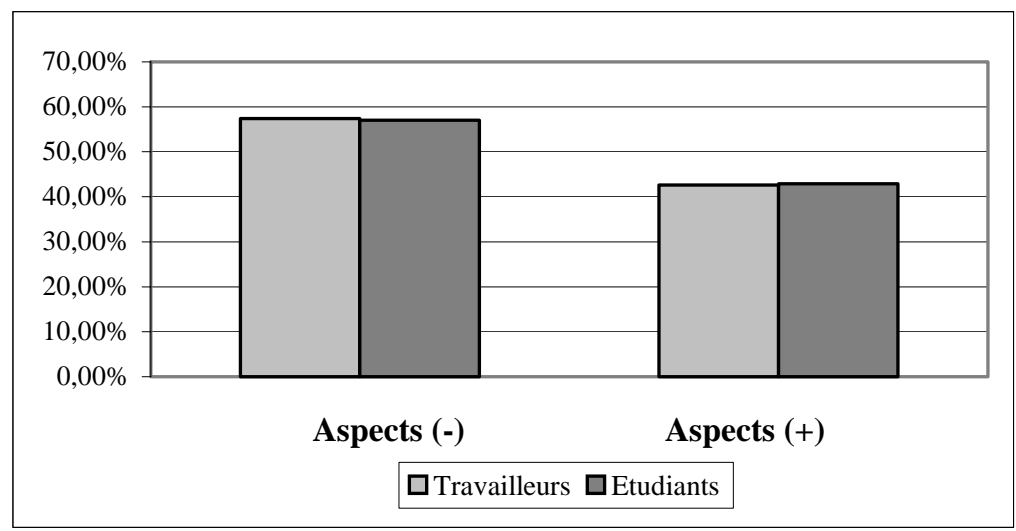

Gráfica 2. Aspectos positivos y negativos que caracterizan al Mexicano. Porcentajes 
Aquí, no se observan grandes diferencias entre poblaciones, y se observa también que tendencialmente son más las palabras negativas (empleados $57.4 \%$, estudiantes $57.1 \%$ ) utilizadas para describir al Mexicano, que las palabras positivas (empleados $42.6 \%$, estudiantes $42.9 \%$ ).

En cuanto a símbolos que mejor representan a México, tenemos en la grafica 3, que destacan tanto los aspectos de orden cívico, que representan en conjunto $40 \%$ del total de respuestas, como los aspectos étnicos, los cuales representan el $42.1 \%$, del total de las respuestas.

En efecto, los aspectos cívicos (36.8\%) son en el caso de los empleados ligeramente más importantes que los aspectos de orden étnico (35.1\%) para describir a México. Mientras que para los estudiantes los aspectos étnicos (49.1\%), resultan más importantes que los aspectos cívicos (43.9\%) en la tarea de caracterizar a México. Los aspectos religiosos ocupan el lugar, en porcentajes, más bajos en cuanto a símbolos del país en los estudiantes (7.0\%) sin embargo, en los empleados constituye un $28.1 \%$ de sus repuestas.

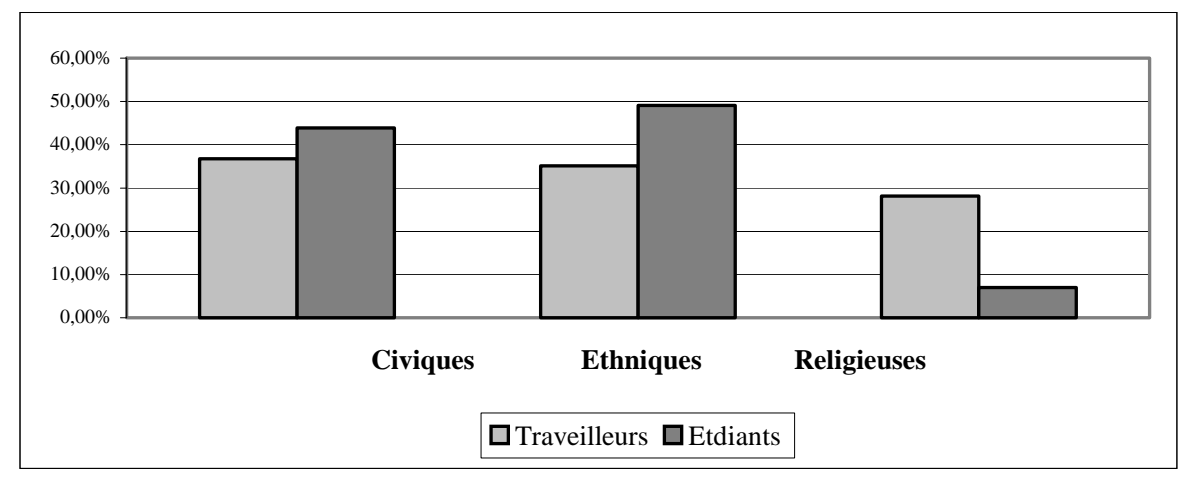

Gráfica 3. Los símbolos asociados a México según su característica.

En cuanto a los símbolos que mejor caracterizan al Mexicano tenemos 3 tipos de símbolos: étnicos, cívicos y religiosos, la grafica 4 , describe los resultados.

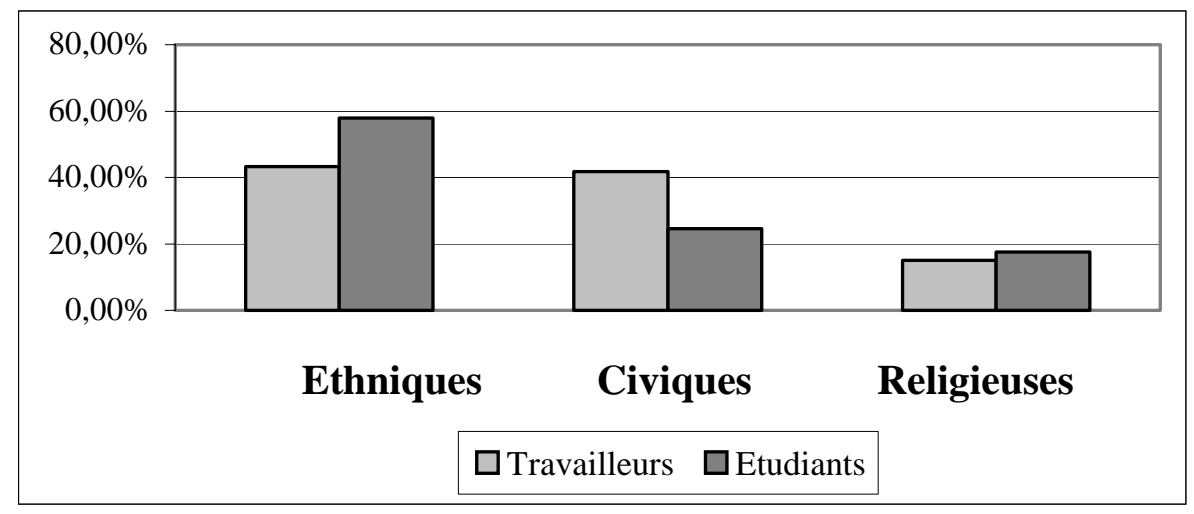

Gráfica 4. Los símbolos asociados al Mexicano según su carácter

Aun cuando los aspectos étnicos parecen el principal aspecto que sirve para caracterizar la Mexicano, pues constituye el $50.4 \%$ del conjunto de respuestas, observamos que para los empleados 
los componentes étnicos y cívicos poseen más o menos el mismo peso en su caracterización, en porcentajes (étnicos $43.3 \%$ / cívicos $41.7 \%$ ), mientras que para los estudiantes aún cuando los dos son importantes, los étnicos tienen mayor peso en la tarea de describir al Mexicano (étnicos 57.9\% /cívicos 24.6\%). Los aspectos religiosos representan los porcentajes más bajos en las dos poblaciones (15\% para empleados y $17.5 \%$ para estudiantes).

Si bien el tamaño de las poblaciones interrogadas no nos permite identificar diferencias importantes en cuanto a los objetos México y el Mexicano, intuimos de inicio un comportamiento distinto entre un conjunto de respuestas y el otro.

Finalmente, presentamos los eventos que mejor caracterizan, por un lado, el origen del país y, por el otro, el origen del Mexicano. Dada la diversidad de eventos a considerar dentro de la lista inicial proporcionada a nuestros sujetos, optamos por agrupar por periodo histórico el conjunto de respuestas, buscamos identificar si había un peso determinado de alguna época de la historia que fuera asociada a los objetos México y Mexicano En la grafica 5 se presentan los resultados que refieren los hechos históricos asociados al origen del país, de la nación mexicana.

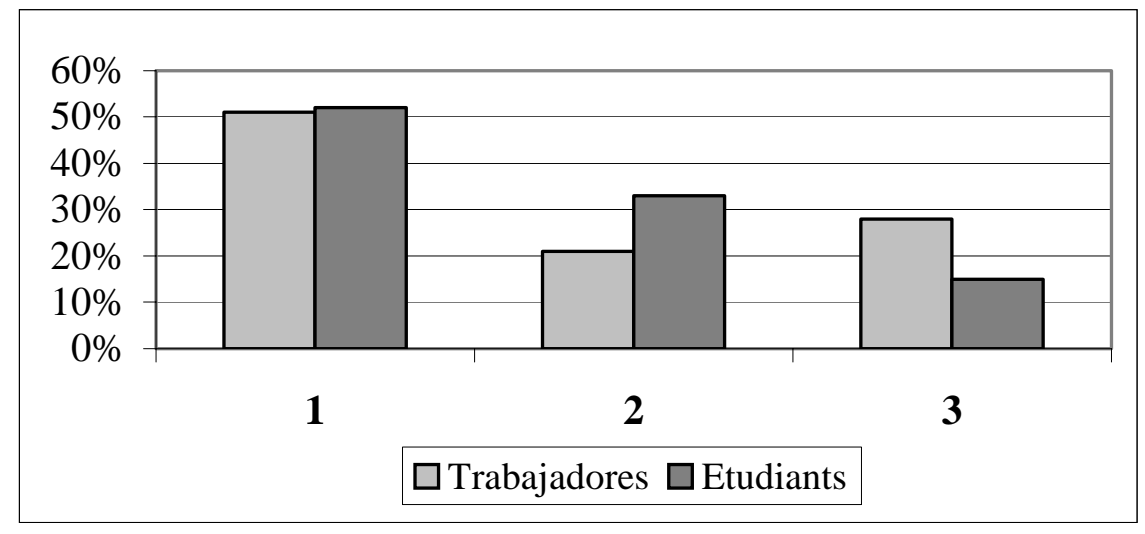

Gráfica 5. Hechos históricos asociados al origen de México

1- México Antiguo, Nuevo mundo y Conquista

2- México Independiente y Revolución

3- México Moderno y Contemporáneo

Tres son los periodos en los cuales dividimos el conjunto de hechos referidos inicialmente en nuestro cuestionario: 1. El México Antiguo (Fundación de Tenochitlán, Siglo XIV), el Nuevo Mundo (el descubrimiento de América) y la Conquista. 2. México Independiente y Revolución (Independencia, intervención francesa y Revolución). 3. México moderno y contemporáneo. (expropiación petrolera, movimiento estudiantil del 68 y los sismos del 85).

Así, en los hechos históricos que explican el origen del país son el México Independiente y la Revolución en las dos poblaciones los más importantes (51\% en empleados, $52 \%$ en estudiantes). Cabe destacar que el peso de esos dos eventos es más o menos el mismo en las dos poblaciones. El segundo grupo de eventos son el México moderno y contemporáneo para los estudiantes (33\%), mientras que para los empleados (28\%) es el México antiguo, el Nuevo mundo y la Conquista. 
Mientras que este ultimo ocupa el tercer lugar para los estudiantes (15\%). En los empleados (21\%) el tercer lugar lo ocupa el México moderno y contemporáneo.

Destaca el lugar que ocupa el México Independiente y la Revolución como explicación en los origines del país.

En cuanto a los hechos históricos que mejor caracteriza los orígenes del Mexicano, se presenta la grafica 6, que reagrupa también los hechos históricos reportados según el periodo al que corresponden.

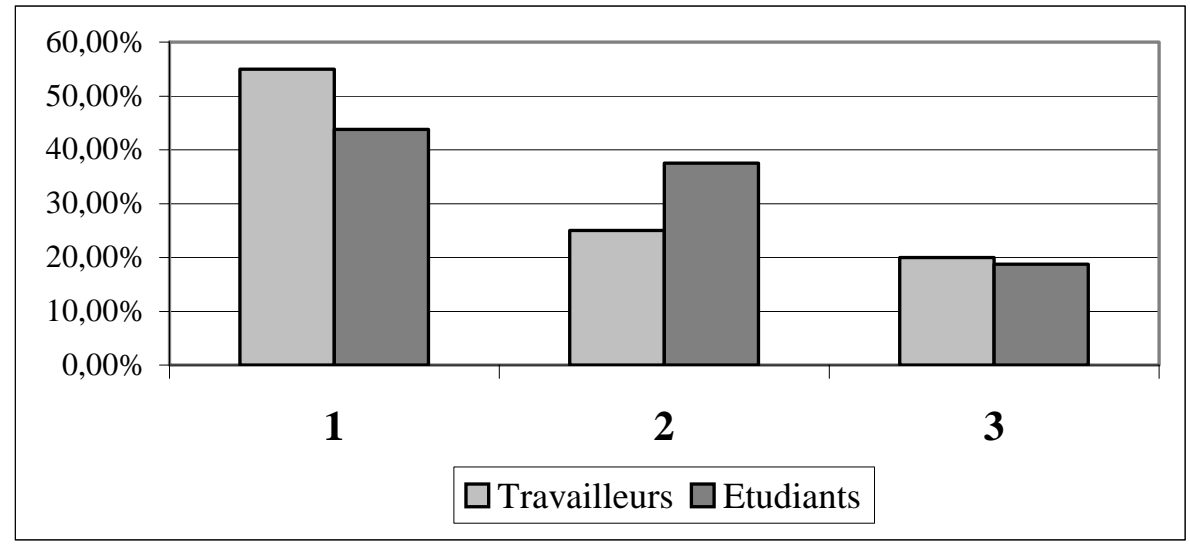

Gráfica 6. Hechos históricos asociados al origen del Mexicano

1- México Independiente y Revolución

2- México Moderno y Contemporáneo

3- México Antiguo, Nuevo mundo y Conquista

En este caso es el México antiguo, el Nuevo mundo y la Conquista el que mejor caracteriza los orígenes históricos del Mexicano según nuestros entrevistados (empleados 55.0\%/ estudiantes 43.8\%), donde destaca la Conquista como referente particular. En segundo lugar destaca el México Independiente y la Revolución para las dos poblaciones (empleados 25.0\% / estudiantes 37.5\%), de modo que el México moderno y contemporáneo, ocupa el tercer lugar en la explicación de los orígenes del Mexicano (empleados 20.0\% / estudiantes 18.8\%).

Destaca aquí el lugar que ocupa el México antiguo, el Nuevo mundo y la Conquista como factor de explicación de los orígenes del Mexicano y de cara al resultado sobre los orígenes de México ubicado más bien en el México Independiente y la Revolución. Con la finalidad de profundizar en el significado de estos eventos, así como el contrastar nuestros resultados en otras poblaciones, se elaboró y realizó una guía de entrevista cuyos resultados se presentan en dos figuras que son el resultado del análisis de contenido realizado con Altas-ti.

\subsection{Los orígenes de México y el Mexicano.}

La ilustración que se presenta (llustración 2), da cuenta de las palabras, nociones, ideas que son asociadas a México y a sus orígenes, donde el mestizaje ocupa un lugar importante para caracterizar o decir lo que es este país, pero sin referencia al hecho histórico que le dio lugar. Igualmente cuando 
se indaga sobre el origen del país aparece la palabra mestizaje como su origen, y más concretamente la Independencia y la escena del águila devorando una serpiente como los hechos históricos que hicieron posible hablar de un origen del país.

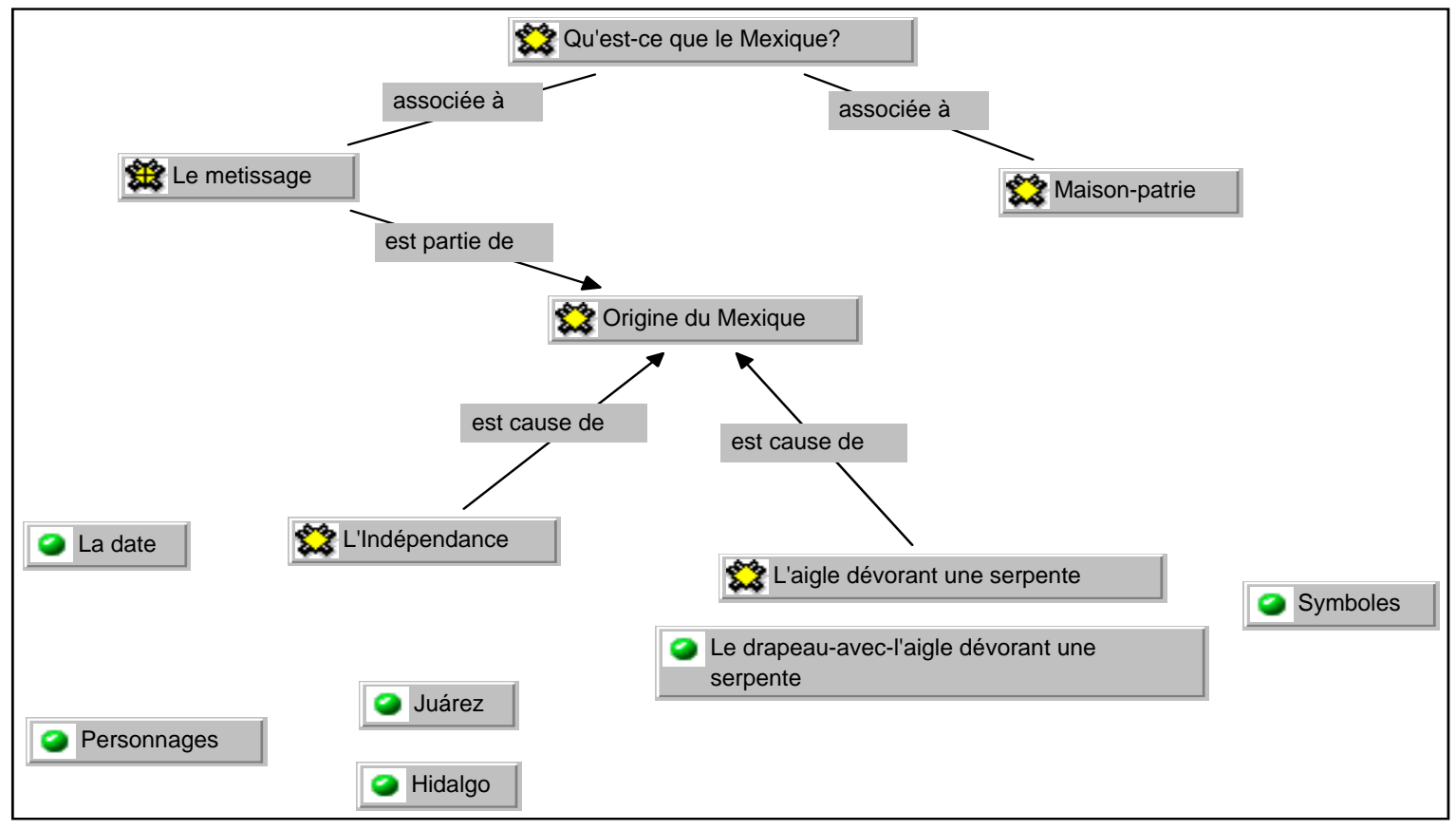

llustración 2. México: sus orígenes y sus símbolos

En cuanto a los símbolos asociados aparecen la bandera, y el emblema del águila devorando a la serpiente, en los personajes históricos que mejor representan a país: Hidalgo y Juárez. Finalmente la fecha más importante para México es el 15 de septiembre, día en que se celebra la independencia de México.

De los orígenes del Mexicano destaca la referencia a los grupos: los indígenas en primer lugar, los mestizos, y los españoles. Aparecen también los eventos históricos: la Conquista, como explicación del origen y la Independencia cuando se indaga sobre la fecha más importante para los Mexicanos. La religión aparece ligada a la Conquista, unas veces para destacar la llegada del cristianismo otras para enfatizar que la conquista además de violenta fue espiritual. Identificamos también connotaciones positivas asociadas a los Indígenas (del pasado), a la Independencia, y connotaciones negativas asociadas a los españoles, la Conquista y la religión.

Los resultados de los diversos estudios realizados, de los cuales reportamos aquí solo una parte, nos permiten suponer que existe una relación de oposición entre Conquista e Independencia, dada la tendencia negativa de la primera y la tendencia positiva del segundo. Oposición que coincide a nivel de sus valores negativos y positivos con las imágenes asociadas al Mexicano, que tiene una tendencia negativa, y las imágenes asociadas a país, que tienen una tendencia positiva. En dicha oposición encuentran también un efecto de complementareidad en la medida que la Conquista considerada como el origen del Mexicano y negativa encuentra en la Independencia considerada 
como el origen del país y positiva el complemento que permite armonizar los orígenes y las identidades colectivas.

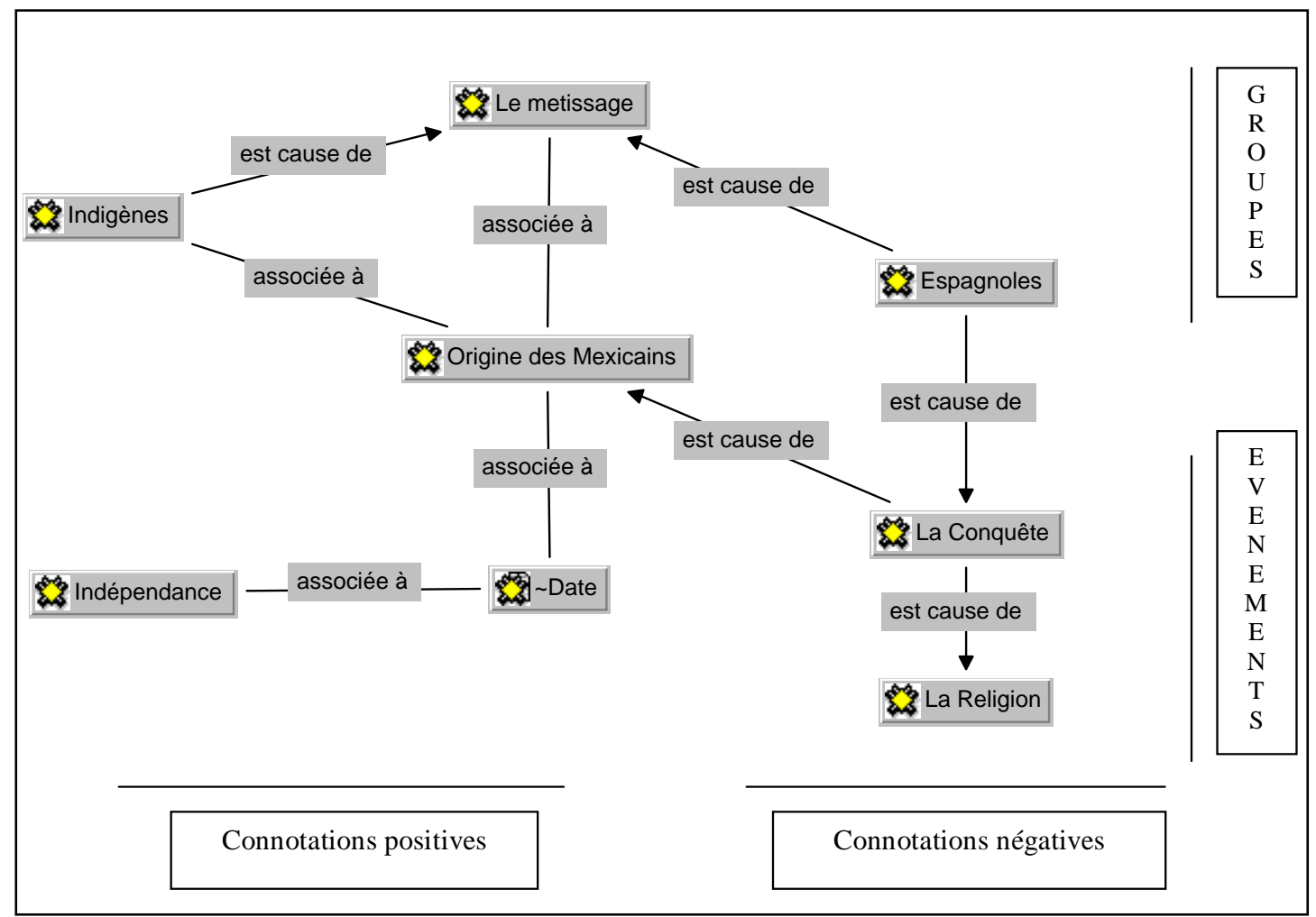

llustración 3. El Mexicano: sus orígenes y sus símbolos

\section{Discusión.}

Aun cuando los resultados que presentamos hasta aquí no son de ninguna manera conclusivos y si resultado de un proceso de exploración sobre el vinculo que existe entre la idea de nación y la identidad nacional considerada ésta como una identidad de orden colectivo, la cual engobla o busca engoblar el resto de las identidades grupales, dichos resultados nos permiten elaborar algunas hipótesis y referentes particulares en el desarrollo de nuestra investigación.

En principio, nos permiten reflexionar de cara a la idea del pensamiento social como una construcción social, simbólica y colectiva que posee, a pesar de las tendencias que existen en nuestra sociedad a la especialización y a la atomización social en diversos ámbitos de la vida cotidiana, una influencia sobre lo colectivo. Así, lo colectivo como eje de sentido, como ideología, creencia no es independiente, ni puede serlo, de lo cotidiano, de las practicas específicas, de los asuntos particulares en medio de los cuales se desenvuelve nuestra vida en sociedad. Intentamos pues entender el vinculo de un eje de sentido que busca ser colectivo, como el de la idea de nación, y su consecuencia la identidad nacional, con las formas propias del pensamiento social. Elegimos es cierto, sólo un aspecto de un tema que siempre resulta complejo y muy abstracto, elegimos a los orígenes en esa búsqueda de sentido y articulación entre México y el Mexicano. Buscamos indagar 
en los símbolos, los personajes y los hechos históricos que explican el origen de uno y de otro, suponíamos de inicio algún tipo de articulación, y más bien de prolongación entre un objeto y otro. Lo indagado hasta aquí nos permite sugerir las siguientes hipótesis.

En ese contexto identificamos dos orígenes, y no insistiremos aquí en la fuerza de los "puntos de partida", en la importancia del primer acontecimiento. Los orígenes son: por un lado, la Conquista para el Mexicano, para el mestizo nacido de ella, y la Independencia y la Revolución para el país. Así la idea de nación resuelve el conflicto de origen de la Conquista, encuentra en la Independencia y también en la Revolución Mexicana la solución histórica y narrativa para construir una imagen de complementareidad de cara a la oposición entre estos eventos.

Así las dos lógicas del origen parecen oponerse y a la vez complementarse, dotando una la Conquista un valor negativo al evento y al Mexicano mientras que la Independencia y la Revolución que tienen asociado un valor positivo como eventos históricos dan sentido al país. Así, la nación aparece protectora del Mexicano, es ella a través de la Independencia y la Revolución que teje un destino diferente para él, cuyo destino originado en la Conquista encuentra en el México independiente la posibilidad de un destino mejor. Es este, al menos así nos parece el fondo de esta identidad colectiva tejida desde las instituciones, tejida desde la historia sí, pero también desde las narraciones que de ella se difunden en el día a día, en el paso del tiempo frente a otras tradiciones y otras narrativas menos conformistas, más aguerridas pero que corresponden menos con esta imagen gloriosa de la nación. Es sin duda, esta una memoria artificial, construida pero goza de una fuerte presencia en las imágenes que del país y del Mexicano circulan en lo cotidiano y que constituyen probablemente, ejes de sentido importantes en la definición del pensamiento social en México.

\section{Referencias}

Anderson (1993) Comunidades imaginadas: reflexiones imaginadas sobre el origen y la difusión del nacionalismo (1 ${ }^{\mathrm{a}}$. Ed.) México: FCE.

Bartlett, Frederic C. (reed. 1995) Recordar. Madrid: Alianza. 1ª. Ed. 1930

Baugnet, L. (1998) L'identité sociale. Paris: Dunod

Cisneros P, Cesar. (1990) México: Memorias Colectivas y Democracia Política en Mota Botello Graciela A. (Coord) Cuestiones de Psicología Política en México. México: UNAM.

Doise, W. (1999). L'individualisme comme représentation collective. In Deschamps, J.-C. M., Fco.,Paez, D.;Worchel, S. (Ed.), L'identité sociale (pp. 195-212). Paris: Presses Universitaires de Grenoble.

Fernández C., P.(2002) Psicología colectiva e historia y memoria, en Flores, F. (Ed) Senderos del pensamiento social, México: Ediciones Coyoacán

Florescano, E. (1996) Los mitos de identidad colectiva y la reconstrucción del pasado. Conferencias del Instituto de Investigaciones Históricas de la UNAM, 3 de Septiembre de 1996.

Halbwachs, Maurice.(1950) La mémoire collective, , Paris : Ed. Albin Michel S.A., 1997.

Hosbawn, E. (1992) Nations et nationalisme depuis 1870, France: Gallimard. 
Páez, D., Valencia, J., N., Herranz, K., González, J.L. (2000). Identidad, comunicación y memoria colectiva. In Alberto, R. R. (Ed.), Memoria Colectiva e Identidad Nacional. España: Biblioteca Nueva.

Pérez-Agote, A. (1993). Las paradojas de la nación. Reis, 7-21.

Rouquette (1994) Sur la connaissance des masses. Grenoble: PUG

Rouquette, M-L. (1988) Psychologie Politique, Paris: PUF.

Znaniecki, F. (1944) Las sociedades de cultura nacional y sus relaciones. México: El Colegio de México.

\section{Formato de citación}

Juárez, J. (2004). México y el mexicano: Identidades colectivas de los orígenes. Athenea Digital, 6. Disponible en http://antalya.uab.es/athenea/num6/juarez.pdf

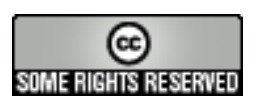

\section{Este texto está protegido por una licencia Creative Commons.}

Usted es libre de copiar, distribuir, exhibir y comunicar la obra bajo las siguientes condiciones:

Reconocimiento: Vd. debe reconocer y dar crédito al autor original.

NoComercial. Vd. no puede utilizar esta obra para fines comerciales.

NoDerivados. $\mathrm{Vd}$. no puede alterar, transformar, o añadir nada a esta obra.

\section{$\underline{\text { Resumen de licencia }}$}

$\underline{\text { Texto completo de la licencia }}$ 